\title{
Modul Step Up Untuk Modem Indihome Menggunakan Arduino Nano Dan Sensor Arus Ina219
}

\author{
Vherda Rifqi Pranata ${ }^{1}$ \\ ${ }^{1}$ Universitas Islam Kalimantan Muhammad Arsyad Al Banjari Banjarmasin \\ Email : vherda.rifqi@gmail.com
}

\begin{abstract}
ABSTRAK
Semenjak menggunakan aplikasi my indihome, teknisi sering mengalami kendala saat pengaktifan modem indihome. Pada skripsi ini, penulis akan membuat alat untuk mempercepat instalasi indihome di rumah pelanggan dengan kabel step up menggunakan Arduino Nano. Alat ini digunakan sebagai pengganti power supply atau adaptor yang harus dihubungan ke sumber listrik. Karena proses instalasi pemasangan indihome yang harus memakan banyak waktu dan jarak yang jauh, maka alat ini dibuat agar waktu yang digunakan teknisi saat mengaktifkan modem bisa bersamaan dengan selesainya instalasi pemasangan dirumah pelanggan dan alat yang dibuat dapat membaca arus dan tegangan untuk modem dengan cara menaikan tegangan dari inputan power bank dari $5 \mathrm{~V}$ ke $12 \mathrm{~V}$ sesuai dengan kebutuhan tegangan dari modem. Sensor INA219 akan membaca apakah tegangan dan arus apakah akan sesuai dengan tegangan yang dibutuhan modem. Keluaran 5V dari power Bank kemudian akan dinaikan oleh modul step up ke 12V. Hasil keluaran tegangan dan arus dari alat tersebut akandi baca oleh sensor untuk menampilkan hasil keluaran dari tegangan dan arus dari modul tersebut. Sehingga dapat dilihat oleh teknisi bahwa tegangan tersebut sesuai dengan kebutuhan modem yang akan di pasang.
\end{abstract}

Kata Kunci: Powerbank, Arduino Nano, Sensor Arus INA219, LCD

\section{PENDAHULUAN}

Ilmu pengetahuan selalu berkembang dan mengalami kemajuan yang sangat pesat, sesuai dengan perkembangan zaman dan perkembangan cara berpikir manusia. Bangsa Indonesia sebagai salah satu negara berkembang tidak akan bisa maju selama belum memperbaiki kualitas sumber daya manusia bangsa kita. Kualitas hidup bangsa dapat meningkat jika ditunjang dengan sistem pendidikan yang mapan. Dengan sistem pendidikan yang mapan, memungkinkan kita berpikir kritis, kreatif dan produktif.

Perkembangan teknologi saat ini di Indonesia mengalami peningkatan yang cukup pesat dan salah satunya adalah teknologi fiber optik. Teknologi ini tidak hanya digunakan dalam bidang telekomunikasi saja, melainkan banyak bidang yang telah menggunakan teknologi ini. Secara umum, kegunaan media transmisi ini adalah menjadi media dalam berkomunikasi dari satu tempat ketempat yang lain. Kelebihan dari media transmisi ini adalah mampu mentransmisikan data yang besar serta berkecepatan tinggi, namun proses instalasi fiber optik saat ini masih membutuhkan waktu yang cukup lama dan membuat teknisi kurang produktif.

Salah satu faktor yang membuat teknisi memakan banyak waktu dalam pemasangan modem indihome terjadi kendala fallout dari sistem maka teknisi harus menunggu informasi perbaikan sistem dari HelpDesk. Modul step up membantu teknisi dalam mengaktifkan modem tanpa harus menghubungkan modem ke sumber listrik secara langsung, sehingga teknisi dapat langsung mengkonfigurasi modem secara langsung. 
Penelitian ini bertujuan untuk menaikan output dayadari tegangan 5Vdan Arus 0.5A dari powerbank ke tegangan $12 \mathrm{~V}$ dan arus $1.5 \mathrm{~A}$ untuk modem indihome serta untuk mengetahui berapa tegangan dan arus yang keluar dari modul step up agar sesuai dengan kebutuhan modem.

\section{METODE}

Tahapan-tahapan yang dilakukan dalam merancang Modul Step Up Untuk Modem Indihome Menggunakan Arduino Nano Dan Sensor Arus Ina219 adalah:

1. Diagram Blok Sistem

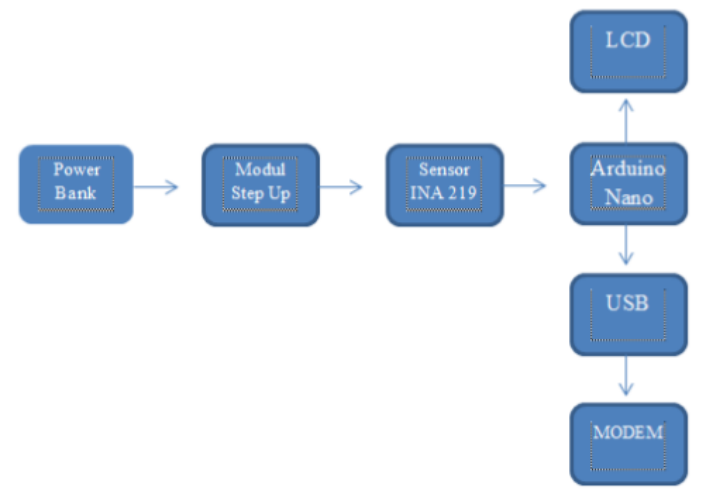

Gambar 1 Blok Diagram Sistem

2. Perancangan Software

a. Powerbank digunakan sebagai sumber tegangan yang diperlukan untuk sistem.

b. Module LM2621 berfungsi untuk menguatkan arus

c. Sensor INA219 berfungsi untuk membaca arus DC

d. Arduino Nano sebagai pemprosesan data untuk mengatur output yang akan di keluarkan ke modem

e. LCD untuk menampilkan data output Tegangan dan arus dari pembacaan sensor INA219.

f. Kabel USB untuk menghubungkan dari arduino ke modem lain:

Untuk memperoleh data dalam penelitian ini menggunakan beberapa langkah antara

1. Penelitian lapangan (Field research)

Peneliti ini dalakukan dengan cara langsung kelapangan untuk memperoleh perbandingan dengan teori dan gambaran sistem.

2. Observasi awal

Melakukan pengamatan langsung ke lapangan dan melakukan wawancara kepada teknisi untuk mengetahui permasalahan dan kendala yang dihadapi saat ini. Berdasarkan hasil observasi dapat diketahui proses aktifasi layanan masih sangat lama apalagi saat di temukan masalah. Dengan penelittian ini diharapkan dapat mempermudah teknisi dalam proses instalasi.

3. Identifikasi Masalah

Melakukan analisis hasil wawancara mengenai kendala dan permasalahan yang sedang dialami teknisi dengan membuat diagram keterkaitan. Berdasarkan informasi yang udah dipetakan melalui diagram keterkaitan, penulis selanjutnya menentukan tujuan enelitian yaitu membuat kebel Step UP guna mempermudah proses intaslai lapangan. 


\section{Studi Pustaka}

Penulis mencari referensi-referensi penelitian terdahulu yang berkaitan dengan tujuan penelitian untuk mengetahui kontribusi penelitian. Penulis juga mencari informasi yang dapat membantu penelitian melalui beberapa referensi.

\section{HASIL DAN PEMBAHASAN}

Hasil pengujian didapatkan data yang ditampilkan di LCD. Dengan modul ini dapat menaikan tegangan dan arus DC lebih tinggi dari nilai tegangan sumber power bank. Seperti output power bank yang tetap $5 \mathrm{~V}$, sementara output yang dibutuhkan modem $12 \mathrm{~V}$. Untuk menaikan tegangan DC dalam sebuah rangkaian elektronika dari $5 \mathrm{~V}$ menjadi $12 \mathrm{~V}$ yaitu dengan menggunakan rangkaian elektronika. Adapun rangkaian utama yang digunakan pada rangkaian tersebut adalah IC LM2621. IC ini merupakan komponen elektronika berupa sirkuit terpadu berbahan semikonduktor. Fungsi IC LM2621 adalah mengontrol dan menguatkan daya (Step Up) serta sebagai fly back. Modul ini dapat menguatkan daya (Step Up) dari $5 \mathrm{~V}$ menjadi $12 \mathrm{~V}$, hasil keluaran tegangan yang sudah $12 \mathrm{~V}$ dapat digunakan untuk suplay power modem. Keluaran IC LM2621 dipasang sensor INA219 untuk mengetahui tegangan dan arus dengan menampilkan pembacaan sensor pada LCD 16x2, sehingga kita dapat mengetahui berapa daya yang tersedia untuk menghidupkan modem.

Selanjutnya pengujian dilakukan pada beberapa bagian, yaitu:

1. Perancangan Hardware

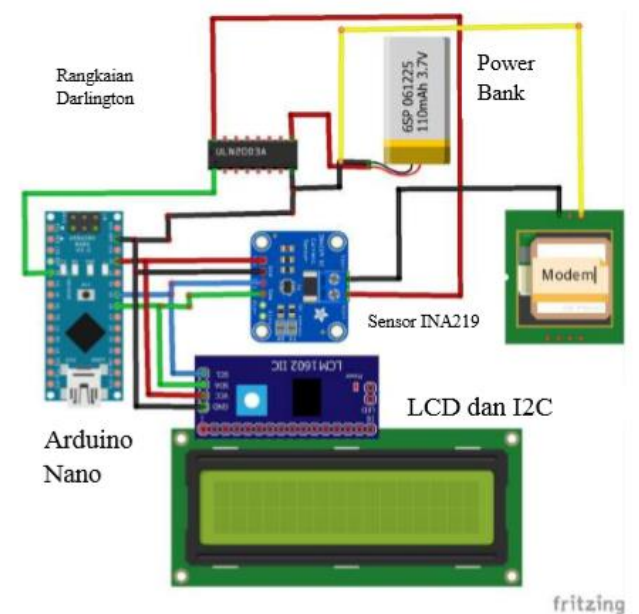

Gambar 2. Perancangan Hardware

Tabel 1. Konfigurasi PIN pada Arduino Nano

\begin{tabular}{|c|c|c|c|c|}
\hline No & $\begin{array}{c}\text { Pin dan } \\
\text { Arduino }\end{array}$ & ULN2003A & $\begin{array}{c}\text { Sensor } \\
\text { INA219 }\end{array}$ & LCD \\
\hline 1 & A4 & & SDA & SDA \\
\hline 2 & A5 & & SCL & SCL \\
\hline 3 & D2 & Input 1 & & \\
\hline 4 & $5 \mathrm{~V}$ & VCC & VCC & VCC \\
\hline 5 & GND & Ground & Ground & Ground \\
\hline
\end{tabular}




\section{Pemproraman Perangkat Lunak}

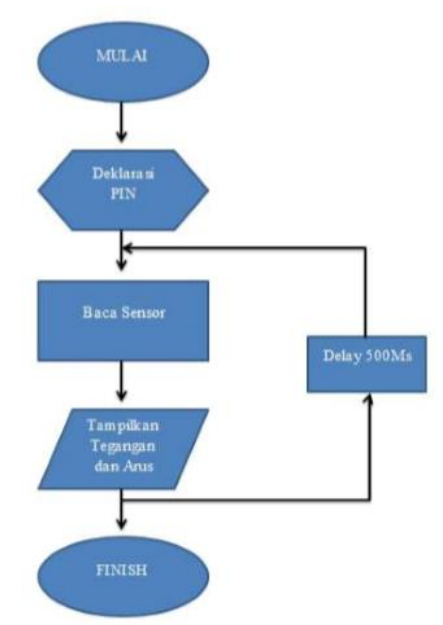

Gambar 3. Flowchart Program Sub Rutin Utama

Alur program utama dimulai dari pendeklarasian PIN untuk menentukan yang digunakan untuk membaca sensor dan menampilkannya di LCD. Kemudian arduino membaca sensor INA219 sebagai sensor tegangan dan arus DC. Setelah itu data tersebut di tampilkan di LCD 16x2. Data akan meupdate perubahan kembali setiap 500ms.

3. Pengujian (Software) perangkat lunak.

Program yang digunakan adalah bahasa $\mathrm{C}$ dengan Arduino IDE ( Integrated Developtment Enviroenment) sebagai software compilernya. Potongan program yang diketik pada Arduino IDE ditunjukkan oleh gambar 2 dan

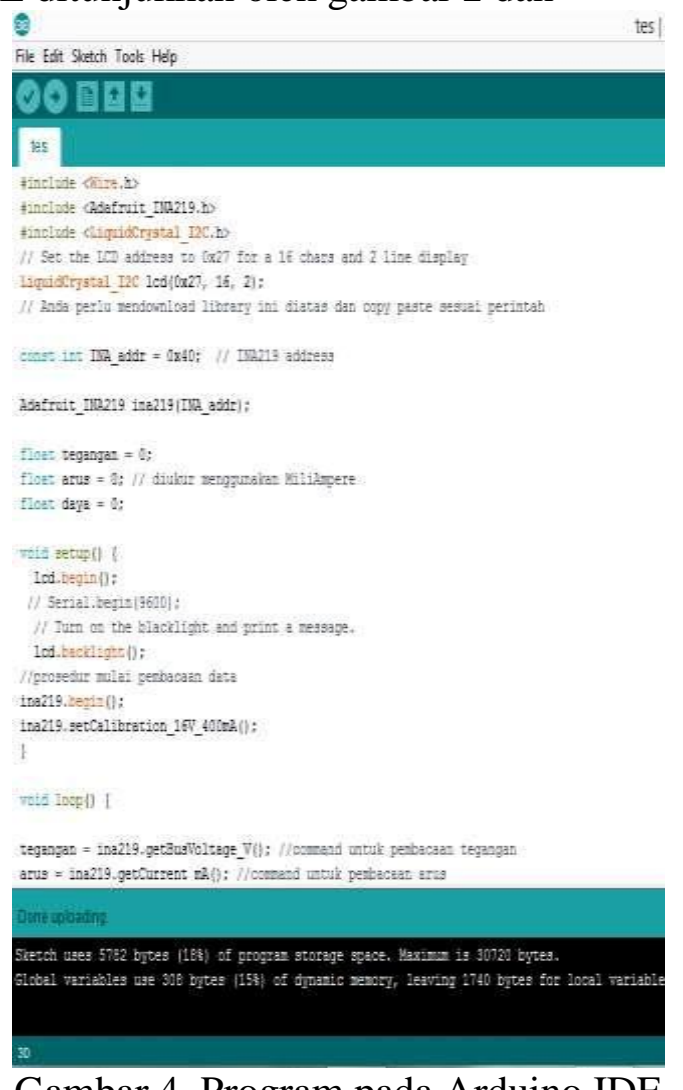




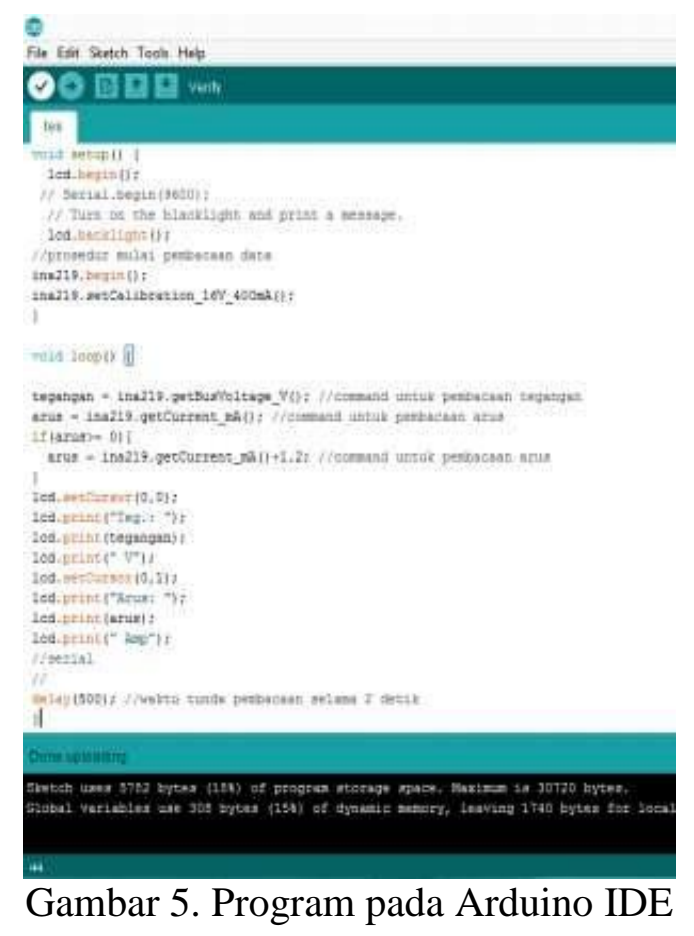

4. Pengujian (Hardware) perangkat keras.

Pengujian perangkat keras bertujuan untuk memeriksa apakah hardware yang akan digunakan dalam projek penulis berjalan secara normal atau tidak, mengetahui cara kerja dari alat ini dan untuk mengetahui apakah perangkat sudah sesuai dengan perencanaan atau belum. Untuk memeriksa hardware dilakukan dengan memberi power pada komponen hardware sesuai spesifikasinya. Kemudian hardware diprogram untuk melihat apakah hasilnya sesuai dengan program yang sudah dibuat. Pengambilan data pengujian dilakukan tiap bagian sistem serta dilakukan pengujian sistem secara keseluruhan.

a. Pengujian Mikrokontroller Arduino Nano

Mikrokontroller Arduino Nano dapat di uji dengan menggunakan program sederhana. Program di buat untuk memastian mikrokontroller bekerjda dan berfungsi normal.

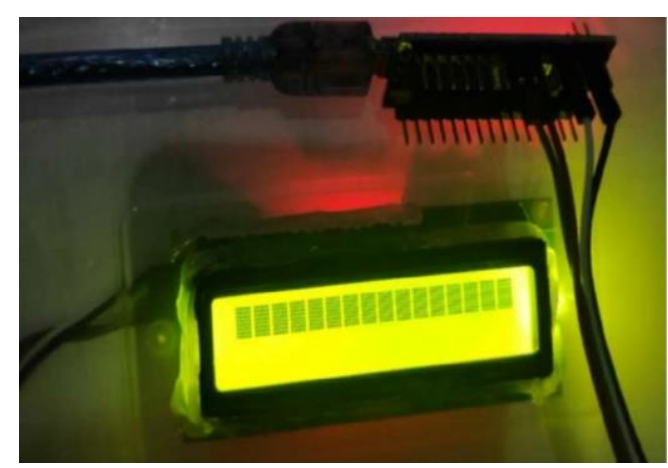

Gambar 6. Pengujian Mikrokontroller Arduino Nano

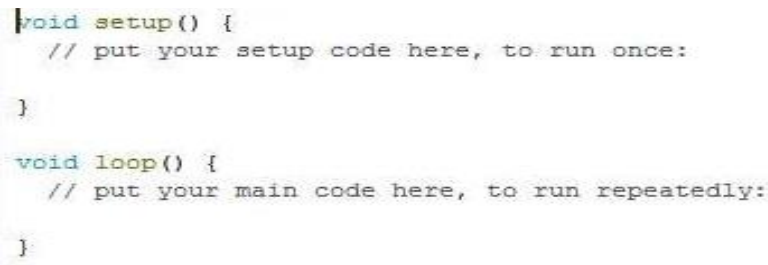

Gambar 7. Script Program Pengujian LCD 16x2 pada Mikrokontroller Arduino Nano 
Dari pengujian mikrokontroller yang di lakukan dapat di ketahui bahwa Mikrokontroller Arduino Nano dalam kondisi bekerja dengan baik, karena saat melakukan pengujian dan program berhasil terupload di Mikrokontroller asrduino nano.

b. Pengujian LCD $16 \times 2$

LCD 16x2 dapat diuji dengn menggunakan program dari example library LCD I2C. Komunikasi I2C yang digunakan menggunakan 2 pin dari mikrokontroller NodeMCU ESP8266 yaitu SDA dan SCL dan untuk menghemat ketersediaan pin pada NodeMCU masih tersedia untuk perangkat lain. Program pengujian yang akan ditampilkan adalah informasi data diri penulis sendiri.

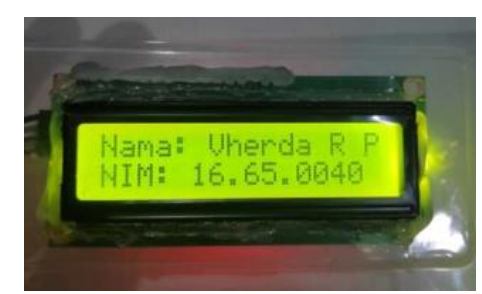

Gambar 8. Pengujian LCD 16x2 pada Mikrokontroller Arduino Nano

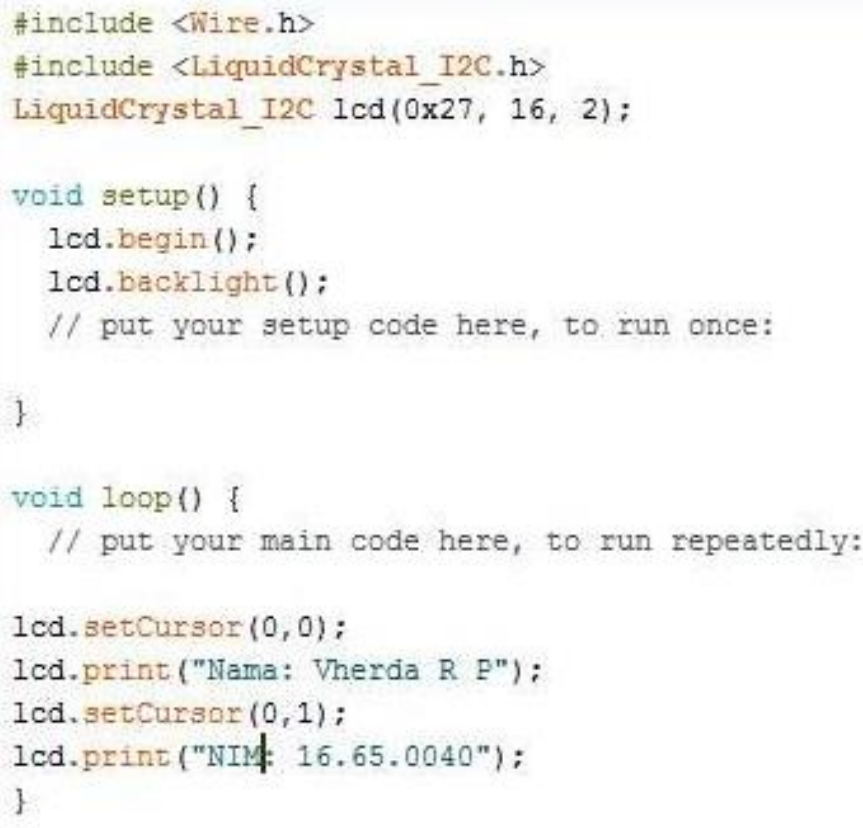

Gambar 9. Script Program Pengujian LCD 16x2 pada Mikrokontroller Arduino Nano

c. Pengujian Sensor INA219

Pengujian sensor arus dilakukan untuk mengetahui karakteristik input output dari Sensor INA219. Pengujian dilakukan dengan cara sensor dialiri arus DC, sensor INA219 diletakkan pada jalur yang menuju beban mdem, sehingga bila ada beban yang menyala maka sensor akan membaca perubahan arus yang mengalir, sedangkan vcc sensor diberi satu daya $5 \mathrm{~V}$. Untuk menampilkan hasil dari pembacaan sensor, digunakan LCD 16x2 sebagai display. 

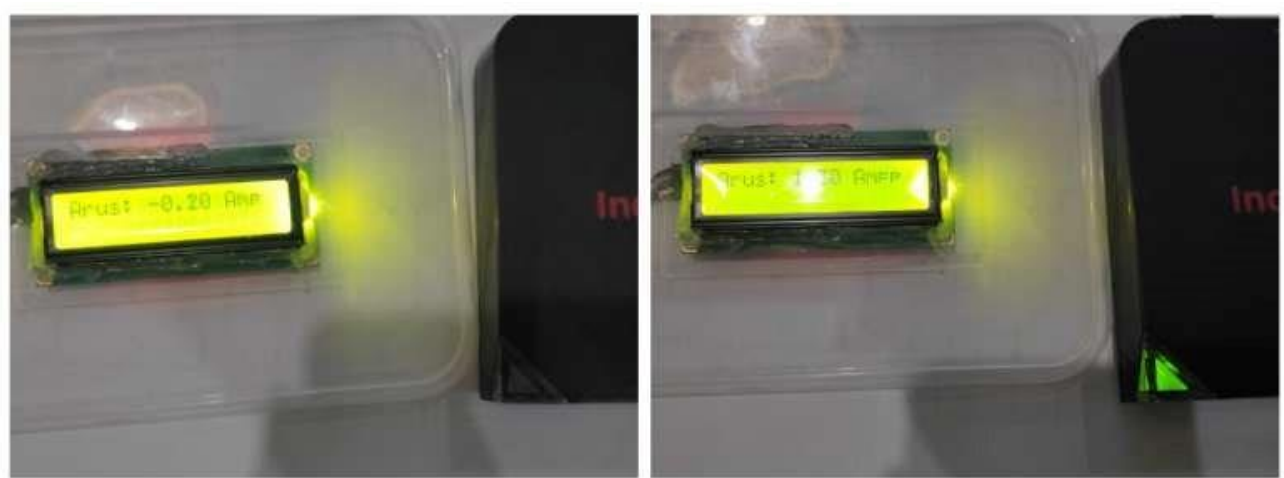

Gambar 10. Pengujian Sensor INA219 pada Mikrokontroller Arduino Nano

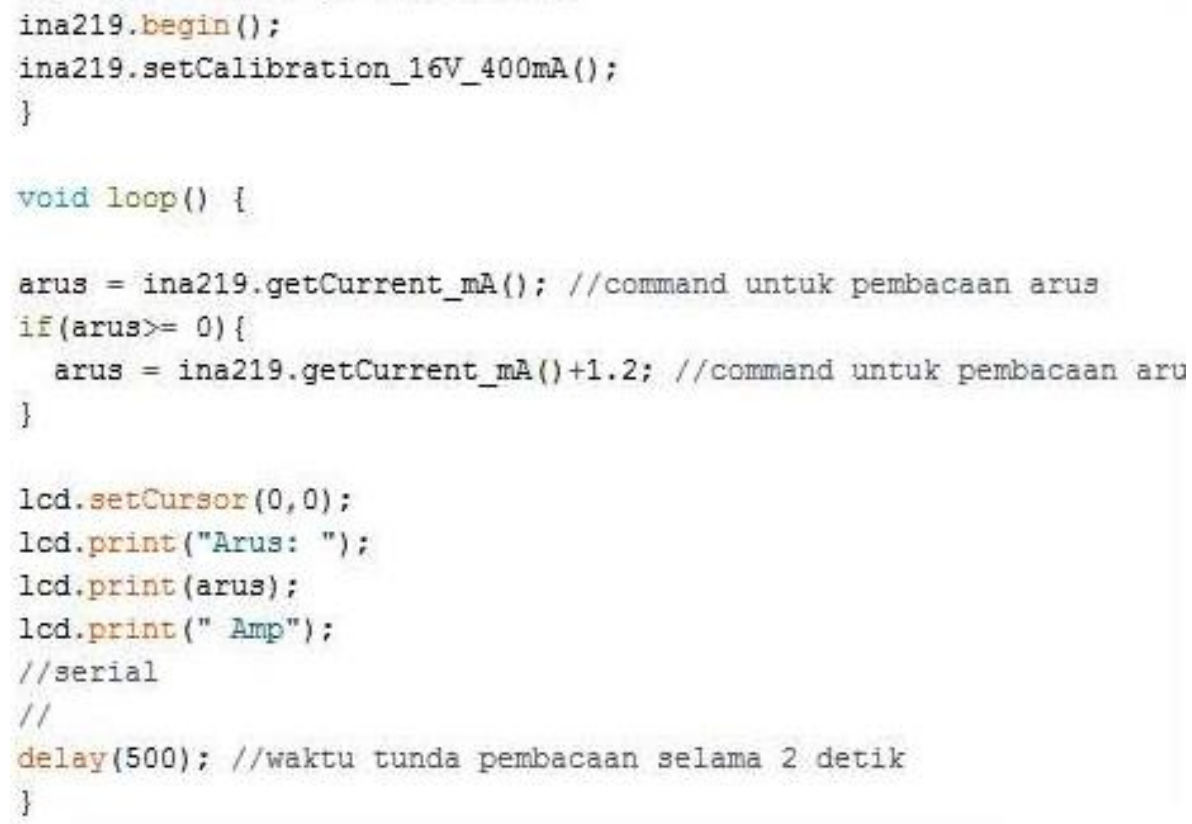

Gambar 11. Script Pengujian INA219 pada Mikrokontroller Arduino Nano

d. Hasil Uji Coba

Tabel 2 Hasil pengukuran arus

\begin{tabular}{|c|l|c|c|c|}
\hline No & $\begin{array}{c}\text { Pengujian } \\
\text { modul }\end{array}$ & $\begin{array}{c}\text { Arus minimum } \\
\text { modem }\end{array}$ & $\begin{array}{c}\text { Arus sebelum } \\
\text { masuk ke modul }\end{array}$ & $\begin{array}{c}\text { Arus sesudah } \\
\text { masuk modul }\end{array}$ \\
\hline 1 & Pengujian 1 & 1 & 0.5 & 1.2 \\
\hline 2 & Pengujian 2 & 1 & 0.5 & 1.3 \\
\hline 3 & Pengujian 3 & 1 & 0.5 & 1.2 \\
\hline 4 & Pengujian 4 & 1 & 0.5 & 1.2 \\
\hline
\end{tabular}




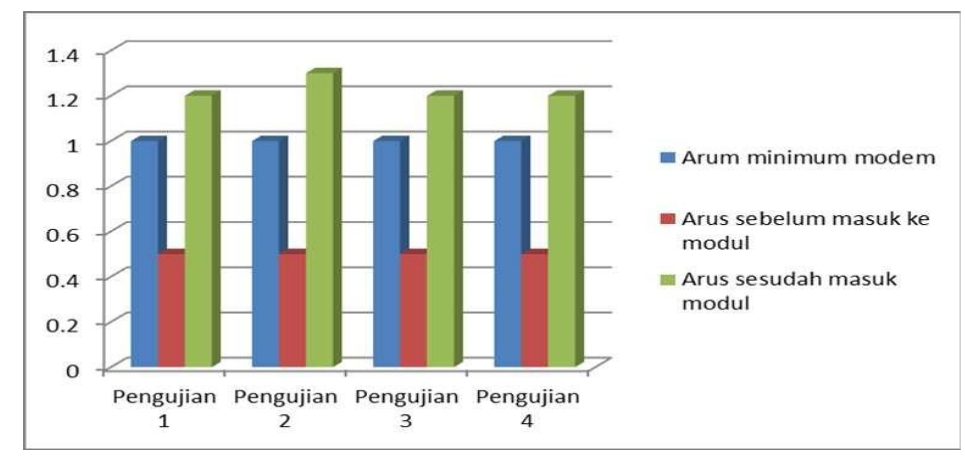

Gambar 12. Grafik pengukuran arus

Dengan arus di bawah 1A modem tidak dapat menyala karena kebutuhan arus minimum pada modem yang tertulis pada spesifikasi ialah 1A. Dengan modul yang di buat arus dapat di naikanmenjadi sebesar 1A yang memenuhi kebutuhan arus minimum pada modem shingga modem dapat menyala dan bekerja.

Tabel 3. Hasil Pengukuran modul Step Up

\begin{tabular}{|c|c|c|c|c|c|}
\hline \multirow{2}{*}{ No } & \multirow{2}{*}{$\begin{array}{c}\text { Pengujian } \\
\text { modul }\end{array}$} & $\begin{array}{c}|c| \\
\text { Megangan } \\
\text { (V) }\end{array}$ & $\begin{array}{c}\text { Arus } \\
(\mathbf{A})\end{array}$ & $\begin{array}{c}\text { Tegangan } \\
(\mathbf{V})\end{array}$ & $\begin{array}{c}\text { Arus } \\
(\mathbf{A})\end{array}$ \\
\hline 1 & Pengujian 1 & 12 & 1 & 12.3 & 1.2 \\
\hline 2 & Pengujian 2 & 12.3 & 1 & 12.3 & 1.3 \\
\hline 3 & Pengujian 3 & 12.3 & 1 & 12.3 & 1.2 \\
\hline 4 & Pengujian 4 & 12.1 & 1 & 12.2 & 1.2 \\
\hline
\end{tabular}

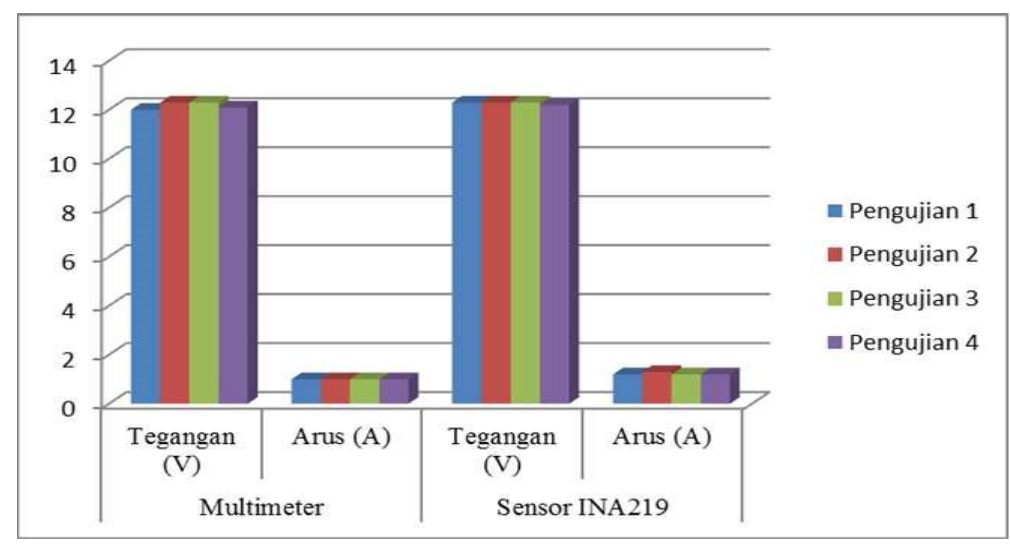

Gambar 13. Grafik pengukuran modul Step Up

Setelah melakukan pengujian dengan multimeter, didapatkan tegangan margin $2.5 \%$ dari $12 \mathrm{~V}$ namun arus tetap sama $1 \mathrm{~A}$ dan terdapat Tegangan $12.3 \mathrm{~V}$ dan Arus 1A yang sama antara Pengujian 1 dan Pengujian 2. Sedangakan dalam pengujian Skrip Program di dapakan hasil tegangan dan arus dengan margin $2.5 \%$ dari $12 \mathrm{~V}$ dan terdapat Tegangan $12.3 \mathrm{~V}$ dan Arus 1.2A yang sama antara Pengujian 1 dan Pengujian 2.

$$
\text { Margin Tegangan }=\frac{0.3}{12} \times 100 \%
$$




\section{KESIMPULAN}

Berdasarkan hasil penelitian, proses pembuatan dan pembahasan mengenai "Kabel StepUP untuk indihome menggunakan arduino nano dan sensor arus INA219" maka dapat diambil beberapa kesimpulan sebagai berikut:

1. Dengan menggunakan module Step UP DC tegangan yang awalnya $5 \mathrm{~V}$ dan arus 0.5 dari powerbank bisa menjadi tegangan $12 \mathrm{~V}$ dan arus $1.5 \mathrm{~A}$.

2. Dengan menggunakan sensor INA219 dan LCD16x2 maka tegangan dan arus dapat di tampilkan pada LCD.

\section{REFERENSI}

Arduino Nano Datasheet, http://roboromania.ro/datasheet/Arduino-Nano roboromania.pdf. Tanggal akses 30 Oktober 2018. Sensor Arus INA219A, https://www.academia.edu/36891729/Artikel_Sensor_Aktuator_Pengukuran_Arus_de ngan_menggunakan_Sensor_Pengukuran_Arus_dengan_INA219. Tanggal akses 30 Oktober 2018.

Module StepUP LM2621, http://www.ti.com/product/LM2621. Tanggal akses 30 Oktober 2018.

Micropower High Efficiency 5V/12V Step UP DC/DC Converter For Flash memory, https://www.analog.com/media/en/technical.../lt1301.pdf. Tanggal akses 30 Oktober 2018.

LCD-016M002B Datasheet. https://www.vishay.com/docs/37217/016m002b.pdf. Tanggal akses 30 Oktober 2018.

User Manual HG8245H Data Sheet https://fccid.io/QISHG8245H/User-Manual/Productmanual-1979642. Tanggal akses 30 Desember 2018. Powerbank, http://www.abrahammaslow.com/teknologi/power-bank-pengertiansejarah-dan-jenis-serta-fungsinyal. Tanggal akses 30 Desember 2018.

STB (Set To Box), https://id.wikipedia.org/wiki/Dekoder_(televisi). Tanggal akses 09 Januari 2019.

Tegangan Listrik, https://id.wikipedia.org/wiki/Tegangan_listrik. Tanggal akses 16 Januari 2019.

Arus Listrik, https://id.wikipedia.org/wiki/Arus_listrik Tanggal akses 16 Januari 2019.

Djuandi, Feri. "Pengenalan Arduino". www.tokobuku.com. Tanggal akses 30 Januari 2019.

Afrizal Fitriadi, Endah komalasari, Herri Gusmedi (2016). "Rancang Bangun Alat Monitoring Arus dan Tegangan Berbasis Mikrokontroler dengan SMS Gate way".

Artanto, Dian, “Interaksi Arduino dan LabVIEW”, Gramedia 2019.

Elih Mulyana (2008). "Pengukuran harmonisasi tegangan dan arus listrik di gedung deriktorat TIK Universitas pendidikan indonesia". Jurnal Pendidikan Jur Elektro

Ir. Anang Supriadi Saleh, Mp dan Amal Bahariawan, STp. MSi, 2018, energi \& elektrifikasi pertanian. CV BUDI UTAMA 